\title{
Comparative study of feeding behaviour of five Mugilidae species juveniles from two estuarine systems in the North Aegean Sea
}

\author{
IOANNA SALVARINA ${ }^{1,2}$, EMMANUIL KOUTRAKIS ${ }^{1}$ AND IOANNIS LEONARDOS ${ }^{3}$ \\ ${ }^{1}$ NAGREF, Fisheries Research Institute, Nea Peramos, Kavala 64007, Greece, ${ }^{2}$ Limnological Institute, University of Konstanz, \\ Mainaustrasse 252, 78464, Konstanz, Germany, ${ }^{3}$ Biological Applications \& Technology Department, University of Ioannina, \\ Ioannina 45110, Greece
}

\begin{abstract}
Food is an important factor for the survival of juvenile fish. Knowledge of the diet of co-existing species helps clarify their relationships with each other. A number of Mugilidae species are known to co-exist in estuarine systems, raising the question of whether they compete for food resources. The feeding behaviours of five juvenile Mugilidae species were studied in the estuaries of Strymonikos (North Aegean Sea) using stomach content analysis. It was found that the species Chelon labrosus, Liza saliens and Mugil cephalus presented high feeding activity during summer and autumn and L. ramada and $\mathrm{L}$. aurata during winter and spring. The diet overlap between the species was generally moderate to low and the pair $\mathrm{L}$. saliens - M. cephalus exhibited the highest overlap in Richios estuarine system. The species do not appear to compete for common resources, probably because there is not always a spatiotemporal overlap, enough food is available or they exploit different resources. Four out of the five species exhibited similar patterns of feeding strategies with varying levels of specialization at an individual level and a rather generalized pattern at the population level. This more generalized feeding strategy may permit them to co-exist. Only M. cephalus showed a more specialized feeding behaviour, with a strong preference for microalgae. The absence of a general pattern for the trophic levels according to seasons, sizes or locations, also imply the opportunistic character of the species. Both season and fish size influenced the variation in the diet composition.
\end{abstract}

Keywords: mullets, diet overlap, feeding strategy, estuarine, stomach content analysis, trophic level, seasonal variations, feeding behaviour, size, Liza

\section{INTRDDUCTION}

The species of the Mugilidae family occur in tropical, subtropical and temperate regions. They are euryhaline and are often found in coastal areas and lagoons. They reproduce in the sea, and the juveniles approach the shore and enter lagoons and rivers, where they grow. They are commercial species that contribute to Mediterranean fisheries. Eight Mugilidae species occur in the Mediterranean Sea (Froese \& Pauly, 2010) of which five occur in Strymonikos Gulf, in the North Aegean Sea (Greece).

Examples of the life aspects of the Greek Mugilidae species studied include seasonal occurrence, size distributions (Koutrakis et al., 1994; Koutrakis, 2004) and phenotypic affinities and short-term seaward migration (Katselis et al., 2006, 2007). Koussoroplis et al. (2010) investigated diet, specifically the nutritional importance of minor dietary sources for Liza saliens during settlement. Studies dealing with Mugilidae diet exist for the rest of the Mediterranean (e.g. AlbertiniBerhaut, 1978; Gisbert et al., 1995; Bartulović et al., 2007, 2009) and their feeding habits are also reviewed by Brusle (1981) and Cardona (2016). However, information regarding feeding during juvenile stages in the Mediterranean is sparse (Albertini-Berhaut, 1978; Cardona, 1999; Bartulović et al., 2009).

Studying the feeding behaviour of fishes is important to clarify the role of species in food webs and ecosystems, the consequences of introduced or invader species, ontogenetic shifts and interspecific relations (reviewed by Stergiou \& Karpouzi, 2002). Dietary information is necessary to estimate trophic level and ecosystem modelling (e.g. Christensen \& Pauly, 1992). For species with economic value, identifying the preferred prey of juveniles is essential to improve production (Ingram \& De Silva, 2007) and manage fish stocks. Knowledge of juvenile feeding behaviour is important because food, among other factors, determines their survival and growth. For commercial fishes it is important also to know if their diet contains species that are potentially toxic, as for example Liza sp. in a large Spanish coastal lake consumed high concentrations of microcystins, higher than the levels for safe consumption by humans (Romo et al., 2012).

Mugilidae are an interesting example of co-occurring species. Their successful co-occurrence might be attributed to distinct feeding habits or migration patterns. The structure of the grey mullet assemblages of the Western Mediterranean estuaries reflects competitive interactions at the fry stage (Cardona et al., 2008). In the coastal lagoons of Strymonikos Gulf, a relatively large number (five) of Mugilidae species coexist. We hypothesized that complex 
competitive interactions occur in relation to their diet. The aim was to examine the feeding behaviour of the juveniles of five coexisting Mugilidae species in the estuarine systems of Strymonikos Gulf and look for possible competition. Estuaries are important areas for Mugilidae species, especially juveniles (reviewed by Koutrakis, 2016). Additional objectives were to study: (i) the seasonal and spatial dietary variations; (ii) the feeding strategy of individual species; (iii) whether the species depend on a common food source and show diet overlap; and (iv) to see if there is behavioural plasticity within species by comparing different estuarine systems, seasons and sizes. We hypothesized that the diet overlap will be rather low within species that coexist in the same estuarine system during the same time. We expected that $L$. aurata will be the most competent species and will have the most generalized diet, as it is present most of the time in the estuarine systems (Koutrakis, 2004). Stomach content analysis was done, which offers higher taxonomic resolution analysis compared with more modern and less laborious and time consuming techniques (e.g. stable isotopes), thus it is suitable to compare the diet of species that co-occur and might use common resources.

\section{MATERIALS AND METHODS}

\section{Study area}

Strymonikos Gulf is situated at the north part of the Aegean Sea and occupies an area of about $540 \mathrm{~km}^{2}$ (Figure 1). This gulf is one of the richest fishing areas in the North Aegean Sea. The fish diversity in the Strymonikos estuaries is among the highest in the Mediterranean Sea, with 55 species (belonging to 20 families) (Koutrakis et al., 2000). The water depth does not exceed $80 \mathrm{~m}$. The gulf is affected by freshwater input from the Strymon and Richios Rivers, which are the main sources of nutrients as well as domestic and agricultural pollutants into the sea (Stamatis et al., 2001). The discharge pattern of the Strymon River shows strong seasonal variability, ranging from $18 \mathrm{~m}^{3} \mathrm{~s}^{-1}$ in August to $122 \mathrm{~m}^{3} \mathrm{~s}^{-1}$ in April,

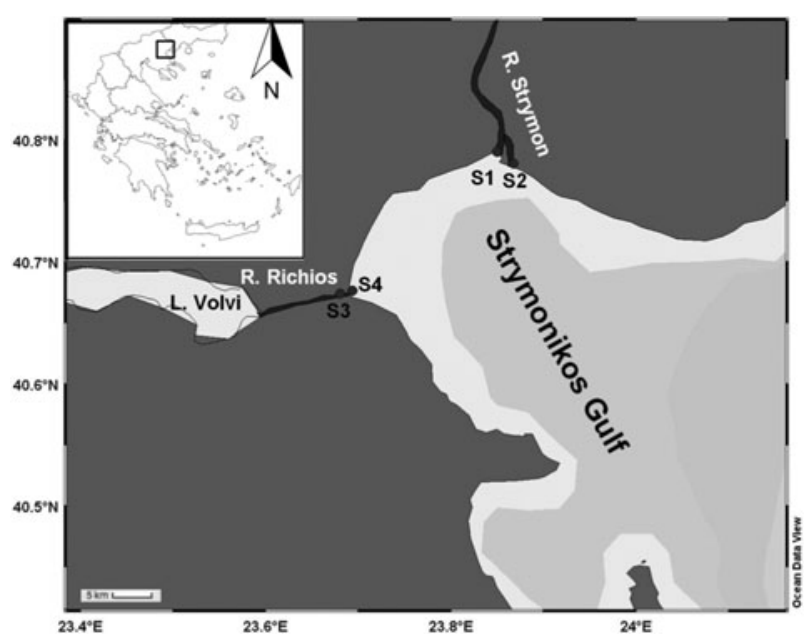

Fig. 1. Map of the sampling area with the sampling stations indicated: $\mathrm{S}_{1}$ and $\mathrm{S}_{2}$ in the Strymon estuarine system and $\mathrm{S}_{3}$ and $\mathrm{S}_{4}$ in the Richios estuarine system. In the top left the broad sampling area is marked in a box on the map of Greece. while the Richios River is relatively constant throughout the year, with a mean annual discharge of $0.90 \mathrm{~m}^{3} \mathrm{~s}^{-1}$ (Koutrakis et al., 2004).

The current study was conducted in the estuarine systems of the two main rivers that flow into Strymonikos Gulf. Strymon, one of the most important rivers in Northern Greece, has its source in Bulgaria and it flows to the northern part of Strymonikos Gulf, forming a small lagoon and several channels. The second river, Richios, drains from Lake Volvi (Greece) and flows to the western part of the gulf, where it creates a small estuarine system. Both rivers are ecologically important sites according to the Greek habitat project Natura 2000, and Richios is also part of the Lake KoroniaVolvi Ramsar site. The riparian vegetation consists of Salix alba and Populus alba galleries, while the submersed vegetation includes aquatic macrophytes. The substrate at the mouth of both rivers is mainly gravel and sand. Seasonal variations in water temperature (ranging from 7.9 to $29.4^{\circ} \mathrm{C}$ ) and the dissolved oxygen (ranging from 1.95 to $14.2 \mathrm{mg} \mathrm{l}^{-1}$ ) are obvious in both areas. The salinity varies according to the location of each sampling station, with lower values (o-13) in the main stream (stations $\mathrm{S}_{1}$ and $\mathrm{S}_{3}$ ) and higher values $(4-35)$ in the estuaries (stations $\mathrm{S}_{2}$ and $\mathrm{S}_{4}$ ) (Koutrakis et al., 2000).

\section{Sampling procedure}

Sampling was conducted monthly during the period of September 1997 to May 1999 at four stations: two stations with different salinity gradients (one at the mouth and one in the course of each river) for each of the two estuarine systems of the Strymonikos Gulf, Richios and Strymon (Figure 1).

The fish were collected using a bag seine net (length $20 \mathrm{~m}$, height $1.5 \mathrm{~m}$, gill net mesh size $2 \mathrm{~mm}$ knot to knot) in water depths of $0.5-1.2 \mathrm{~m}$. The fish were placed in a $6 \%$ neutralized formalin solution and were transferred to the laboratory, where they were identified to species level according to Cambrony (1984) and their total length (TL, mm) was measured. The stomachs were extracted and kept separately in a $6 \%$ neutralized formalin solution for diet analysis.

\section{Diet analysis}

Cumulative prey curves were constructed for each species to examine whether the number of stomachs examined was sufficient to describe the diet. These plots were created with PRIMER (Clarke \& Gorley, 2001) using 999 permutations to ensure the samples were in random order (Campo et al., 2006). Linear and non-linear regressions were fitted to the curves, and because the coefficient of variation $\left(R^{2}\right)$ of the non-linear model was higher than that of the linear model, the curves were assumed to reach an asymptote (Castriota et al., 2005; Campo et al., 2006). Therefore, the number of stomachs examined was sufficient for the description of the diet.

To determine the importance of each food category in the diet of each species, the per cent volume $(\% \mathrm{~V})$ and the frequency of occurrence (\%FO) (Hyslop, 1980) were calculated. The percentage volumetric composition $(\% \mathrm{~V})$ is the volume of a food category divided by the total volume of all food categories in the stomach. It is expressed as a percentage after pooling the stomach contents of all specimens for each species separately. The percentage volumetric composition 
was calculated for each species for each estuarine system, for each season, and for each size class. The fishes were grouped into three size classes (I: $<30 \mathrm{~mm}$, II: $30-50 \mathrm{~mm}$, III: $>50 \mathrm{~mm}$ ). The number of the size classes was selected as a compromise so that each class had enough samples for the analysis.

The frequency of occurrence $(\% \mathrm{FO})$ is the percentage of stomachs in which an undigested food category was present. Stomachs with digested contents were discarded from all analyses. The vacuity index (VI\%) was estimated for each species as VI\% $=$ (number of empty stomachs)/(total number of stomachs examined) $\times 100$ (Hureau, 1966). The fullness index was estimated using the subjective scale of Lebedev (1946), with o for an empty stomach and 5 for a full stomach. The mean fullness index was calculated per species, estuarine system and season separately.

\section{Data elaboration}

The diet overlap between the different species was calculated using Schoener's overlap index, a robust measure of diet similarity (Wallace, 1981):

$$
S=1-0.5\left(\sum_{i=1}^{n}\left|p_{x i}-p_{y i}\right|\right)
$$

where $p_{x i}$ and $p_{y i}$ are the proportions of food item $i$ in the diet of species $x$ and $y$, respectively, and $\mathrm{n}$ is the number of food categories (Schoener, 1970). The index takes values from o (no overlap) to 1 (total overlap). The index was calculated for each pair of species that co-occurred in each estuarine system in each season.

To describe the main sources of variation, a correspondence analysis, a suitable ordination method for community ecological data was used (Digby \& Kempton, 1987). This was done separately for the number of food items and for the fullness index of fish captured by species and sampling season (matrix of 5 species $\times 4$ seasons). The effect of size class, season and species on the total volume of consumed food, was tested with a general linear model (glm) analysis. For both of the above-mentioned analyses samples from the different estuarine systems were pooled, as the sampling size was not always adequate to perform the analysis separately for each system. All above statistical analyses were performed using SPSS v. 18.

To test how the different variables (species, estuarine system, size and season) explained the variation in diet composition (matrix with volumetric contribution of all food items) permutation multivariate analysis of variance (permanova) was conducted using the 'adonis' function from the package 'vegan' in R ( $\mathrm{R}$ Development Core Team, 2012), with 1000 permutations and method 'bray'.

To test whether detritus and microalgae were accidentally consumed while preying on other benthic items, linear regressions were done between the benthic food items collectively (Amphipoda, Chironomidae, Decapoda, Polychaeta, other worms, unidentified insects and other macroinvertebrates) and detritus and microalgae, respectively.

To search for differences in the feeding activity between the two different salinity locations in each estuarine system, the fullness index between the station with the low salinity (St. 1 and St. 3) and high salinity (St. 2 and St. 4) was compared per each species and for all species together, taking into consideration the season. General linear models were used for these analyses that were conducted using RStudio (RStudio Team, 2015, Version 0.98.932).

The feeding strategy of the studied species was illustrated with the aid of the Costello method (modified by Amundsen et al., 1996) in a diagram with the prey-specific abundance (\%Pi) on the $y$ axis and the frequency of occurrence (FO) (range $0-1$ ) on the $x$ axis. The prey-specific abundance $P_{\mathrm{i}}$ of each food item i was calculated as $P_{\mathrm{i}}=\left(\sum S_{\mathrm{i}} / \sum S_{\mathrm{ti}}\right) \times 100$, where $S_{\mathrm{i}}=$ the total volume of food item $i$ in all stomachs and $S_{\mathrm{ti}}=$ the total stomach content volume only of those stomachs in which food item $\mathrm{i}$ is included. This illustration method provides information on prey importance, feeding strategy, and contribution of the food items in the niche width, through the position of food items in the two-dimensional plot, and it shows whether the feeding strategy is specialized or generalized. The diagonal axis from the lower left to the upper right corner is a measure of prey importance for the population. The vertical axis represents the feeding strategy in terms of specialization or generalization. The diagonal axis from the upper left to lower right shows the contribution of food items to the niche width.

The trophic level (TROPH) per season for each estuarine system for each species is based on the following equation (Pauly et al., 1998, 2000): $\mathrm{TROPH}_{\mathrm{i}}=1+\sum_{j=1}^{G} D C_{\mathrm{ij}} \times \mathrm{TROPH}_{j}$ where $\mathrm{TROPH}_{j}$ is the fractional trophic level of prey $j, D C i j$ is the fraction of prey $j$ in the diet of $i$, and $G$ is the total number of prey species. The TROPH for each species was estimated from the V\% contribution of each food item in the species diet using the quantitative routine of TrophLab (Pauly et al., 2000). The TrophLab's default trophic levels for the food items were used. More information about how the trophic levels are attributed to the prey items can be found in FishBase and the FishBase Book (Froese \& Pauly, 2010). The trophic level for each individual and then the mean value for each season, location and species was calculated. The mean values for each size class for each species (using samples from all seasons and locations) were also calculated. To compare the mean trophic levels among the above-mentioned groups Kruskal-Wallis (when $>_{2}$ groups) or Mann-Whitney-Wilcoxon (when 2 groups) test was used, as the data were not normally distributed. To test how season and size class explain the variation in trophic level, general linear models were used per species and per system. Similar models were also used to test the effect of size class and season on explaining the variation in individual food items per species and system, when those food items seemed to have a trend with size or season. These analyses were done in $\mathrm{R}$.

\section{RESULTS}

\section{Sample}

All five Mugilidae species that occur in Strymonikos Gulf were caught: thicklip grey mullet Chelon labrosus (Risso, 1827), thin-lip grey mullet Liza ramada (Risso, 1827), golden grey mullet L. aurata (Risso, 1810), leaping mullet L. saliens (Risso, 1810) and flathead grey mullet Mugil cephalus (Linnaeus, 1758). A total of 823 specimens was examined. Their total length ranged from 14 to $130 \mathrm{~mm}$ (Table 1 ). The 
Table 1. Number of specimens (N) examined, vacuity index (VI\%) and total length (mean \pm standard deviation, minimum and maximum values; TL, $\mathrm{mm}$ ) of each Mugilidae species collected during the current study, per species, season and estuarine system and mean from all specimens per species.

\begin{tabular}{|c|c|c|c|c|c|c|}
\hline Species & Estuarine system & Season & $\mathbf{N}$ & Vacuity index & Total length (min-max) & Total length $($ mean $\pm \mathrm{SD})(\mathrm{mm})$ \\
\hline \multirow[t]{9}{*}{ C. labrosus } & \multirow[t]{4}{*}{ Strymon } & Summer & 35 & 8.57 & $19-61$ & $36.74 \pm 10.96$ \\
\hline & & Autumn & 12 & 25.00 & $49-110$ & $80.67 \pm 16.96$ \\
\hline & & Winter & & & & \\
\hline & & Spring & 21 & 57.14 & $19-98$ & $27.57 \pm 21.08$ \\
\hline & \multirow[t]{4}{*}{ Richios } & Summer & 33 & 3.03 & $21-78$ & $52.30 \pm 15.62$ \\
\hline & & Autumn & 11 & 18.18 & $51-121$ & $76.55 \pm 24.13$ \\
\hline & & Winter & 3 & 33.33 & $59-114$ & $91.00+28.58$ \\
\hline & & Spring & 9 & 33.33 & $22-82$ & $34.44 \pm 23.76$ \\
\hline & All & All & 124 & 20.16 & $21-121$ & $48.26 \pm 25.29$ \\
\hline \multirow[t]{9}{*}{ L. aurata } & \multirow[t]{4}{*}{ Strymon } & Summer & & & & \\
\hline & & Autumn & 64 & 12.50 & $24-43$ & $31.31 \pm 3.87$ \\
\hline & & Winter & 36 & 27.78 & $19-37$ & $29.25 \pm 4.76$ \\
\hline & & Spring & 88 & 4.55 & $22-72$ & $43.51 \pm 11.54$ \\
\hline & \multirow[t]{4}{*}{ Richios } & Summer & & & & \\
\hline & & Autumn & 9 & 77.78 & $27-40$ & $33.00 \pm 4.21$ \\
\hline & & Winter & 32 & 50.00 & $28-45$ & $33.75 \pm 3.79$ \\
\hline & & Spring & 41 & 26.83 & $21-72$ & $40.76 \pm 9.77$ \\
\hline & All & All & 270 & 18.15 & $19-72$ & $36.79 \pm 9.97$ \\
\hline \multirow[t]{9}{*}{ L. ramada } & \multirow[t]{4}{*}{ Strymon } & Summer & 2 & 50.00 & $25-29$ & $27.00 \pm 2.83$ \\
\hline & & Autumn & 5 & 20.00 & $18-21$ & $20.60 \pm 1.52$ \\
\hline & & Winter & 24 & 79.17 & $17-22$ & $20.25 \pm 1.36$ \\
\hline & & Spring & 22 & 4.55 & $20-74$ & $44.73 \pm 23.33$ \\
\hline & \multirow[t]{4}{*}{ Richios } & Summer & 18 & 5.56 & $16-130$ & $30.17 \pm 26.83$ \\
\hline & & Autumn & 1 & 100.00 & 70 & 70 \\
\hline & & Winter & 4 & 100.00 & $17-24$ & $19.50 \pm 3.11$ \\
\hline & & Spring & 41 & 41.46 & $19-72$ & $28.66 \pm 12.83$ \\
\hline & All & All & 117 & 38.46 & $16-130$ & $29.85+18.56$ \\
\hline \multirow[t]{8}{*}{ L. saliens } & \multirow[t]{3}{*}{ Strymon } & Summer & 21 & 42.86 & $17-54$ & $25.52 \pm 8.51$ \\
\hline & & Autumn & 28 & 10.71 & $15-75$ & $51.21 \pm 13.67$ \\
\hline & & $\begin{array}{l}\text { Winter } \\
\text { Spring }\end{array}$ & 7 & 57.14 & $17-45$ & $29.71 \pm 10.87$ \\
\hline & \multirow[t]{4}{*}{ Richios } & Summer & 31 & 25.81 & $14-50$ & $29.52 \pm 10.71$ \\
\hline & & Autumn & 42 & 30.95 & $18-78$ & $37.39 \pm 15.08$ \\
\hline & & Winter & 1 & 100.00 & 20 & 20 \\
\hline & & Spring & & & & \\
\hline & All & All & 130 & 29.23 & $14-78$ & $36.02+15.42$ \\
\hline \multirow[t]{9}{*}{ M. cephalus } & \multirow[t]{4}{*}{ Strymon } & Summer & & & & \\
\hline & & Autumn & 48 & 89.58 & $23-30$ & $26.38 \pm 1.83$ \\
\hline & & Winter & 18 & 94.44 & $22-36$ & $25.56 \pm 2.85$ \\
\hline & & Spring & 1 & 100.00 & 23 & 23 \\
\hline & \multirow[t]{4}{*}{ Richios } & Summer & 8 & 0.00 & $27-40$ & $33.38 \pm 5.01$ \\
\hline & & Autumn & 78 & 11.54 & $22-42$ & $28.12 \pm 3.94$ \\
\hline & & Winter & 29 & 17.24 & $22-50$ & $26.31 \pm 4.80$ \\
\hline & & Spring & & & & \\
\hline & All & All & 182 & 41.21 & $22-50$ & $27.32+3.94$ \\
\hline All species & All & All & 823 & 28.19 & $14-130$ & $35.32+16.19$ \\
\hline
\end{tabular}

vacuity index from all the specimens together was $28.19 \%$. Liza aurata had the lowest vacuity index (18.15\%), and $M$. cephalus had the greatest (41.21\%).

\section{Diet composition}

In total 15 main food items were recorded in the species' stomachs. The species' diets mostly included amphipods, macrophytes, detritus, unidentified insects, microalgae and copepods (Tables $2 \& 3$ ). The results of the permanova showed that all factors, i.e. species, season, estuarine system and size, explained the variation $(P=0.001)$ in the diet composition (Table 4 ). The same was also true when permanova analysis was done separately per species.
The diet composition differed according to season and estuarine system (Table 2). The diet of C. labrosus included mostly amphipods $(\leq 73 \% \mathrm{~V}$ in autumn), macrophytes $(\leq 58 \% \mathrm{~V}$ in spring), unidentified insects $(\leq 47 \% \mathrm{~V}$ in summer) and detritus ( $\leq 39 \% \mathrm{~V}$ in summer) in Strymon; in Richios, it consumed mostly microalgae $(\leq 58 \% \mathrm{~V}$ in autumn and $85 \% \mathrm{~V}$ in winter but only two specimens were analysed in that season), macrophytes ( $\leq 45 \%$ in spring), amphipods $(\leq 42 \% \mathrm{~V}$ in summer), Cirripedia ( $\leq 34 \%$ in spring) and detritus $(\leq 34 \% \mathrm{~V}$ in autumn).

The species L. aurata in Strymon consumed mainly mysids ( $\leq 54 \% \mathrm{~V}$ in spring), followed by unidentified insects ( $\leq 51 \%$ in winter) and amphipods ( $\leq 34 \% \mathrm{~V}$ in autumn). In Richios, it consumed copepods $(\leq 46 \% \mathrm{~V}$ in winter), Chironomidae 


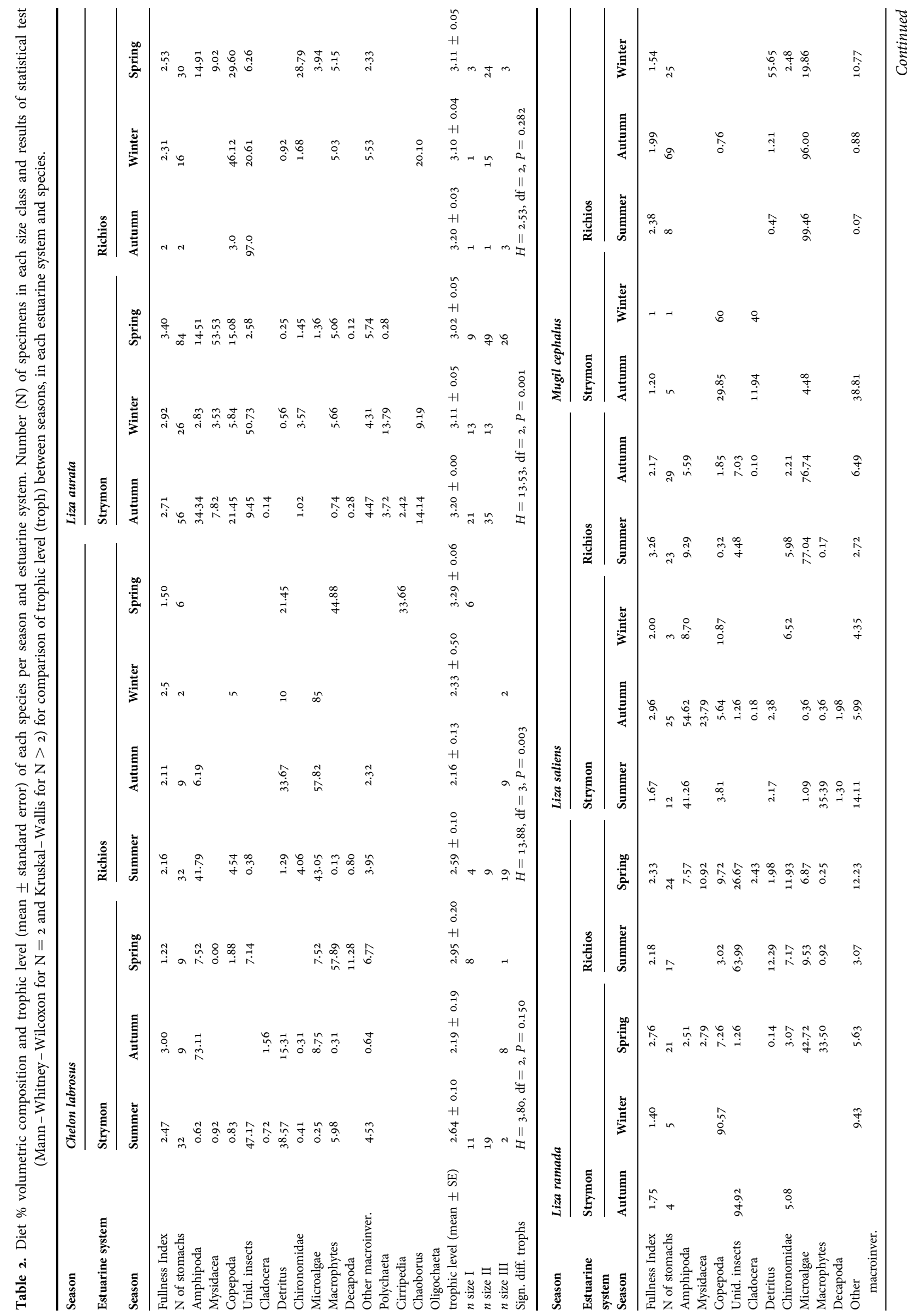




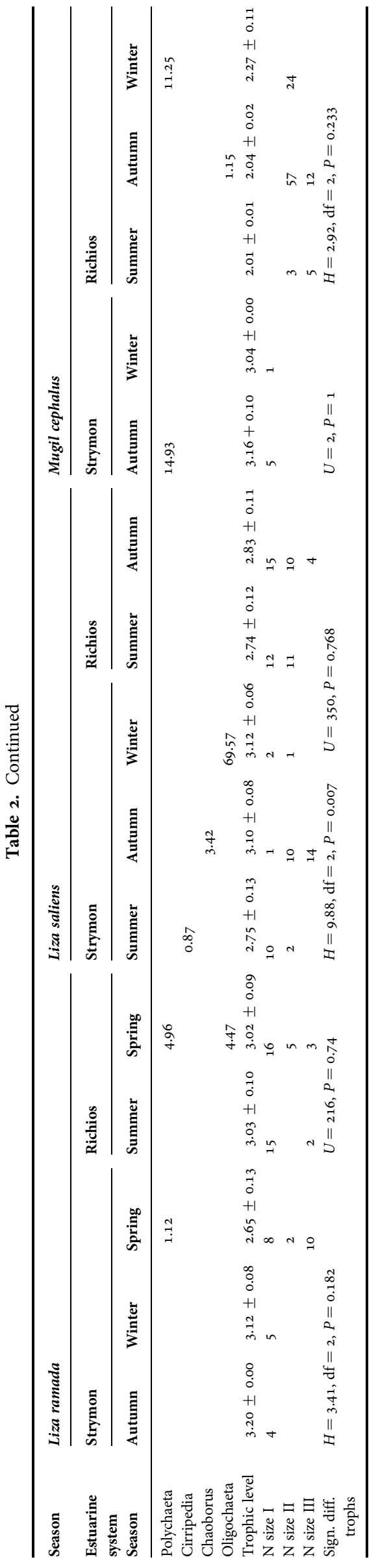

( $\leq 29 \%$ in spring) and other insects ( $\leq 21 \%$ in winter), while the few specimens caught in autumn had consumed almost exclusively unidentified insects $(97 \% \mathrm{~V})$.

Liza ramada at both study sites showed a preference for unidentified insects $(\leq 95 \% \mathrm{~V}$ in autumn in Strymon and $64 \% \mathrm{~V}$ in summer in Richios), but in Strymon, it also consumed a high percentage of copepods $(\leq 91 \% \mathrm{~V})$ in winter and microalgae $(\leq 43 \% \mathrm{~V})$ in spring.

The preferred food items for L. saliens in Strymon were oligochaetes ( $\leq 70 \%$ in winter), amphipods ( $\leq 55 \% \mathrm{~V}$ in autumn) and macrophytes ( $\leq 35 \% \mathrm{~V}$ in summer). In Richios, the species showed a tendency for microalgae $(\leq 77 \% \mathrm{~V}$ both in summer and autumn).

Mugil cephalus also showed differences in its diet between the two regions, as it consumed mostly unidentified invertebrates $(39 \% \mathrm{~V}$ in autumn) and copepods $(60 \% \mathrm{~V}$ in winter) in Strymon; in Richios, it consumed microalgae almost exclusively in summer and autumn $(\leq 99 \% \mathrm{~V})$, and it consumed detritus $(\leq 56 \% \mathrm{~V})$ in winter.

The frequency of occurrence (FO\%) of food items on some occasions was in accordance with their volumetric composition, for example, for microalgae in $M$. cephalus (100\% FO and $96-99 \% \mathrm{~V}$ in summer and autumn in Richios) and in general terms for the food items consumed by L. aurata. However, the food items with the highest frequencies of occurrence (FO\%) were not always the same as those with the highest volumetric contribution to a species' diet. For example, although microalgae was found in all stomachs (100\%FO) of C. labrosus during autumn in Richios, the corresponding contribution in volumetric composition was lower $(58 \% \mathrm{~V})$. The opposite was recorded for other food items with higher volume, such as oligochaetes in the diet of L. saliens in winter in Strymon $(70 \% \mathrm{~V}, 33 \% \mathrm{FO})$. No linear correlation between the microalgae or detritus and the benthic prey was found $(P>0.05)$.

When the specimens were divided into size classes, the volumetric composition ( $\mathrm{V} \%$ ) of their diet in most cases showed some differences according to size (Table 3). Liza saliens and M. cephalus in Richios in particular showed a shift in microalgae after $50 \mathrm{~mm} \mathrm{SL}$, which started earlier $(30-50 \mathrm{~mm})$. This is not related to seasonal differences, at least in $L$. saliens, as a similar consumption of microalgae was observed in both seasons when the species was present in Richios (Table 3). Also, the glm analysis showed that only size class $(P<0.016)$ and not season $(P>0.328)$ explained the variation of the microalgae percentage composition in L. saliens in Richios. Another trend towards microalgae is also shown in C. labrosus in Richios, while L. aurata in Richios, after $50 \mathrm{~mm} \mathrm{SL}$, shows a shift towards Chironomidae (Table 3). As glm analyses showed, in both these cases, the size class explained significantly the variation in microalgae and Chironomidae respectively, and season had no effect. Another noticeable trend is that the contribution of amphipods and mysids increased with length in L. saliens in Strymon (Table 3), but these two were not statistically significant (as resulting from glm).

The first two dimensions in the correspondence analysis of the fullness index in relation to species and sampling season cumulatively explained $96 \%$ of the variation. The species C. labrosus, L. saliens and M. cephalus, which presented a high degree of feeding activity during summer and autumn, were grouped at the left of the graph, while the remaining $L$. ramada and $L$. aurata, which were feeding more intensely 


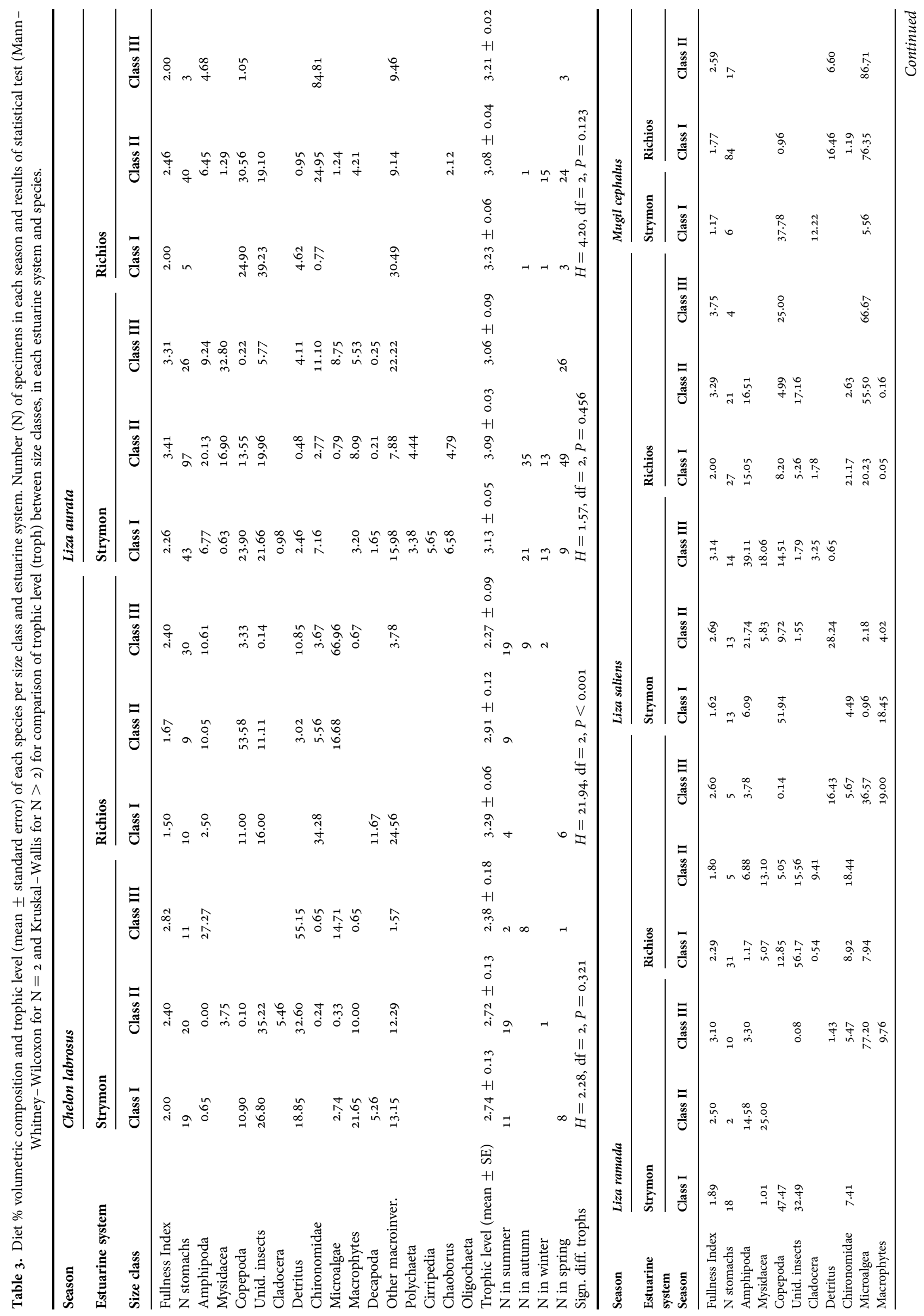




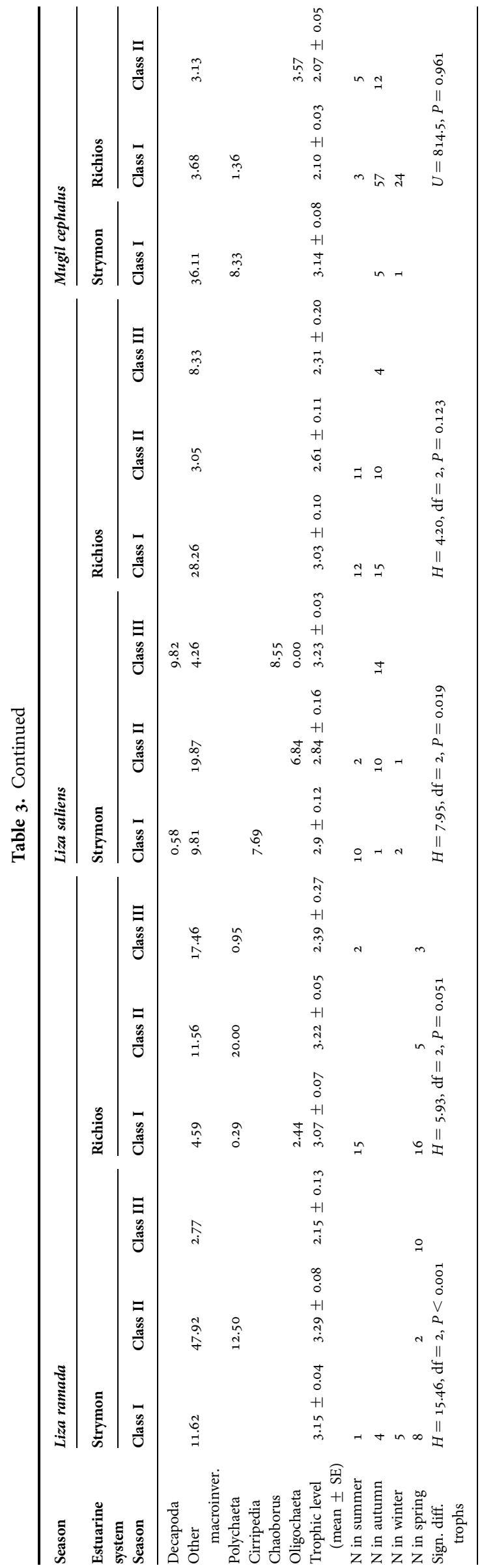

during winter and spring, were grouped at the right part of the graph (Figure 2). The same results (not shown here) appeared when the number of food items in relation to the species and sampling season was examined. The first two dimensions explained $99 \%$ of the variation. The glm analysis performed on the total food volume showed that only the species $(P=$ 0.015) had an effect, not the season or the size class. This result indicates that the volume consumed was not influenced by the season and/or size class, but was dependent on the species.

The variance in the fullness index was influenced by the different salinity station more than the season (station: $P<0.001$ and season: $P=0.034$ in Strymon and station: $P=0.012$ in Richios) when all the species and seasons were accounted together and compared within each estuarine system. When we tested each species separately for each estuarine system, the different salinity station was not found to influence the fullness index $(P>0.05)$ in any species.

\section{Diet overlap}

The pair of species with the highest overlap was $L$. saliens $-M$. cephalus $(0.771-0.784$ on a scale of $0-1)$ in summer and autumn in Richios. Some pairs of species exhibited a moderate overlap, such as C. labrosus-L. saliens in autumn in Richios (0.657), and other pairs had no diet overlap, such as $L$. ramada-M. cephalus in autumn in Strymon (Table 5). The results of diet overlap agree with the volumetric composition of diet (Tables $2 \& 3$ ).

\section{Feeding strategy}

The lack of food items in the upper right section of the diagrams shows that the species $L$. aurata, L. ramada and $L$. saliens had a broader niche width (Figure 3). At the population level, their feeding strategy was rather generalized; hence, many of their food items are concentrated in the lower left section of the diagrams. The species C. labrosus and $L$. saliens had some specialization at individual rather than at population level. Only M. cephalus seemed to have a more specialized feeding strategy, with a relatively stronger preference for microalgae. This preference, however, represents mostly the feeding habits of individuals of the species in Richios system, as the vast majority of individuals $(\mathrm{N}=$ 101 in Richios vs 6 in Strymon), with food in their stomach, were caught in Richios. The points located in the upper left of the diagrams indicate specialization by the subgroups of a population. Such is the case, for example, for amphipods and mysids in the diet of C. labrosus, for Cirripedia in the diet of $L$. aurata and $L$. saliens, for vegetation in the diet of $L$. ramada, and for Chironomidae in the diet of $M$. cephalus. At the individual level, generalization was also recognized, as many food items are located in the lower half of the diagram (e.g. amphipods, cladocerans and Chironomidae in the diet of L. ramada). Most of the food items had varying levels of rarity and contributions to the niche width of each population.

\section{Trophic levels}

For the trophic levels estimated for each species per season and per estuarine system (Table 2), it seems that C. labrosus had the highest value in spring in Richios $(3.29 \pm 0.06)$ and 
Table 4. Results of permutation multivariate analysis of variance (permanova), method $=$ bray, permutations $=1000$ for the diet composition of all species, seasons, size classes and estuarine system.

\begin{tabular}{lrrrrrr}
\hline & DF & $\begin{array}{c}\text { Sum of } \\
\text { squares }\end{array}$ & $\begin{array}{c}\text { Means } \\
\text { Squares }\end{array}$ & F.Model & $\boldsymbol{R}^{\mathbf{2}}$ & $\boldsymbol{P}$ \\
\hline Species & 4 & 26.908 & 6.727 & 18.168 & 0.104 & 0.001 \\
Season & 3 & 7.859 & 2.620 & 7.075 & 0.031 & 0.001 \\
Estuarine system & 1 & 3.473 & 3.473 & 9.381 & 0.014 & 0.001 \\
Size & 2 & 7.267 & 3.634 & 9.814 & 0.028 & 0.001 \\
Residuals & 573 & 212.16 & 0.370 & & 0.823 & \\
Total & 583 & 257.668 & & & 1 & \\
\hline
\end{tabular}

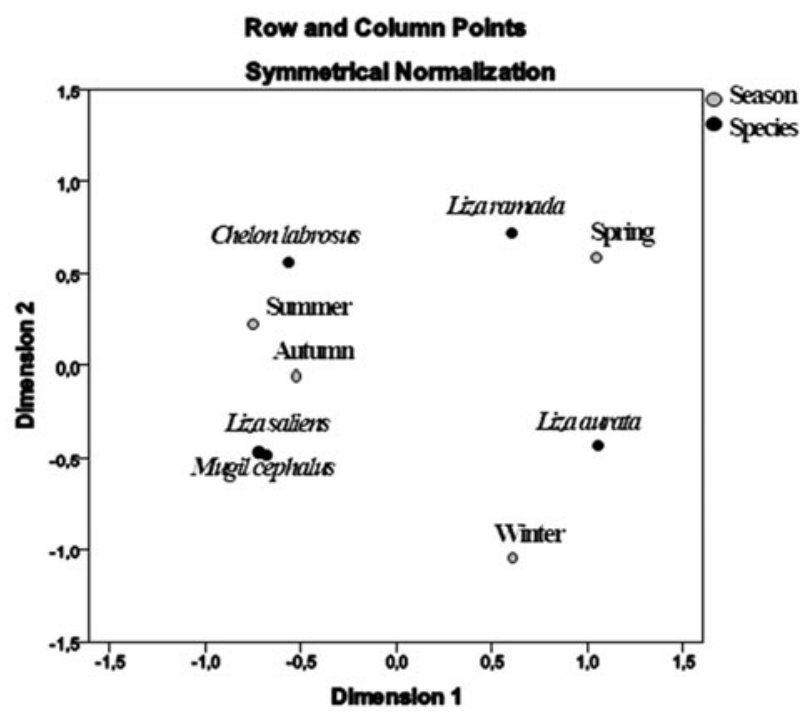

Fig. 2. Ordination of the Mugilidae species and season, based on the two first axes of the correspondence analysis performed on the fullness index of samples collected in the estuarine systems of Strymonikos Gulf (Strymon and Richios).

L. aurata in Strymon and Richios in autumn $(3.20 \pm 0.00$ and $3.20 \pm 0.03)$ while the lowest value overall was recorded for M. cephalus in summer in Richios $(2.01 \pm 0.01)$.

In terms of the trophic levels between different seasons, locations and species there appears to be no general pattern. Liza aurata had a nearly constant trophic level in all cases
(3.02-3.20), while variation of up to 1.15 trophic levels existed in e.g. M. cephalus, from 2.01 in summer in Richios to 3.16 in autumn in Strymon (Table 2). In most of the cases the trophic level did not differ between seasons for the same location and species (Kruskal-Wallis test, $P>0.05$ ) (Table 2). Only L. aurata and L. saliens had significantly different trophic levels between seasons in Strymon $(H=13.53$, $\mathrm{df}=2, P=0.001$ and $H=9.88, \mathrm{df}=2, P=0.007$, respectively) and $C$. labrosus in Richios $(H=13.88, \mathrm{df}=3, P=$ 0.003). When the trophic levels between the two different locations were compared per species (samples from all seasons together), difference was found only for M. cephalus ( $U=22, P<0.001$ ).

When we plotted the data (plots not shown here) there was no clear linear relationship between the trophic level and fish size for any of the species. There was no general pattern of the effect of size class and season on the trophic level, but it instead varied between species and systems (Tables $3 \& 6$ ). For $M$. cephalus neither season nor size explained the variation in trophic level. In the rest of the species, either season or size played a role, but only for L. saliens in Strymon did both parameters explain significantly the variation in trophic level. In general in Richios, season had no importance, while in Strymon season and/or size class explained the variation of trophic level (Table 6). The slight increase in the trophic level of $L$. ramada was mainly from the first to the second size class, while there was a decrease in the third size class (Table 3 ).

\section{DISCUSSIDN}

\section{Diet composition}

The diets of juvenile Mugilidae in the two estuarine systems of Strymonikos Gulf consisted of 15 broad food categories, with specific food items prevailing in each species' diet. Our results agree with most of the other studies concerning Mugilidae species (Eggold \& Motta, 1992; Bartulović et al., 2007; Koussoroplis et al., 2010), however differences were also found (Bartulović et al., 2009). Mugilidae fry are considered zooplanktophagous (Cardona, 2001; El-Ghobashy, 2009), with a preference in copepods, cladocerans and Chironomidae (Gisbert et al., 1995, 1996). Mugilidae species are known to

Table 5. Diet overlap between a pair of Mugilidae species that co-occur in each season and each estuarine system during the sampling period of the current study. C.l., Chelon labrosus; L.a., Liza aurata; L.r., Liza ramada; L.s., Liza saliens; M.c., Mugil cephalus. The higher values are in bold. Note: although L. aurata, C. labrosus and M. cephalus were present in autumn in Richios, in winter in Richios and in winter in Strymon respectively, they were not considered for the diet overlap calculations due to the low number of specimens with food in their stomach $(\mathrm{N}=2, \mathrm{~N}=2$, and $\mathrm{N}=1$, respectively).

\begin{tabular}{|c|c|c|c|c|c|c|c|c|}
\hline \multirow[t]{2}{*}{ Species } & \multicolumn{4}{|c|}{ Strymon estuarine system } & \multicolumn{4}{|c|}{ Richios estuarine system } \\
\hline & Summer & Autumn & Winter & Spring & Summer & Autumn & Winter & Spring \\
\hline C.1-L.a & & 0.357 & & 0.243 & & & & 0.052 \\
\hline C.1-L.r. & & 0.003 & & 0.523 & 0.215 & & & 0.022 \\
\hline C.1.-L.s. & 0.144 & 0.585 & & & 0.599 & 0.657 & & \\
\hline C.1.-M.c. & & 0.067 & & & 0.436 & 0.599 & & \\
\hline L.a.-L.r. & & 0.105 & 0.101 & 0.277 & & & & 0.510 \\
\hline L.a.-L.s. & & 0.577 & 0.165 & & & & & \\
\hline L.a.-M.c. & & 0.298 & & & & & 0.081 & \\
\hline L.r.-L.s. & & 0.013 & 0.152 & & 0.232 & & & \\
\hline L.r.-M.c. & & o & & & 0.101 & & & \\
\hline L.s.-M.c. & & 0.122 & & & 0.771 & 0.784 & & \\
\hline
\end{tabular}




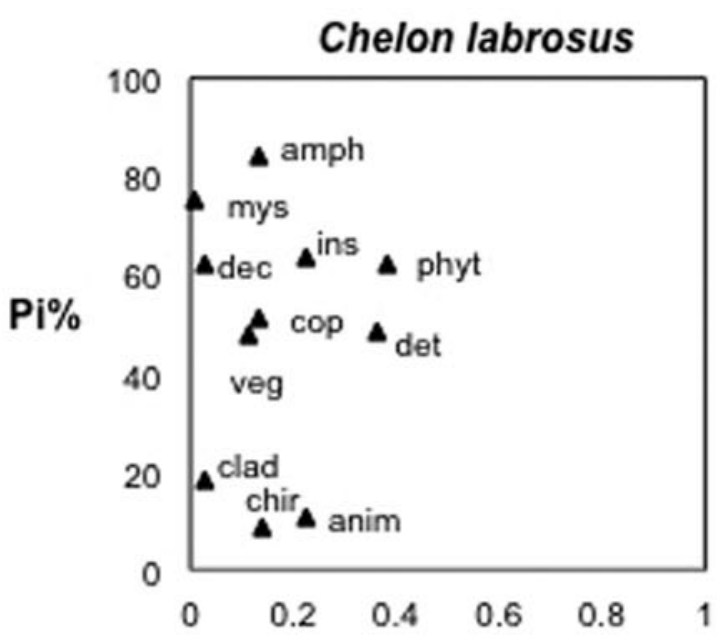

FO
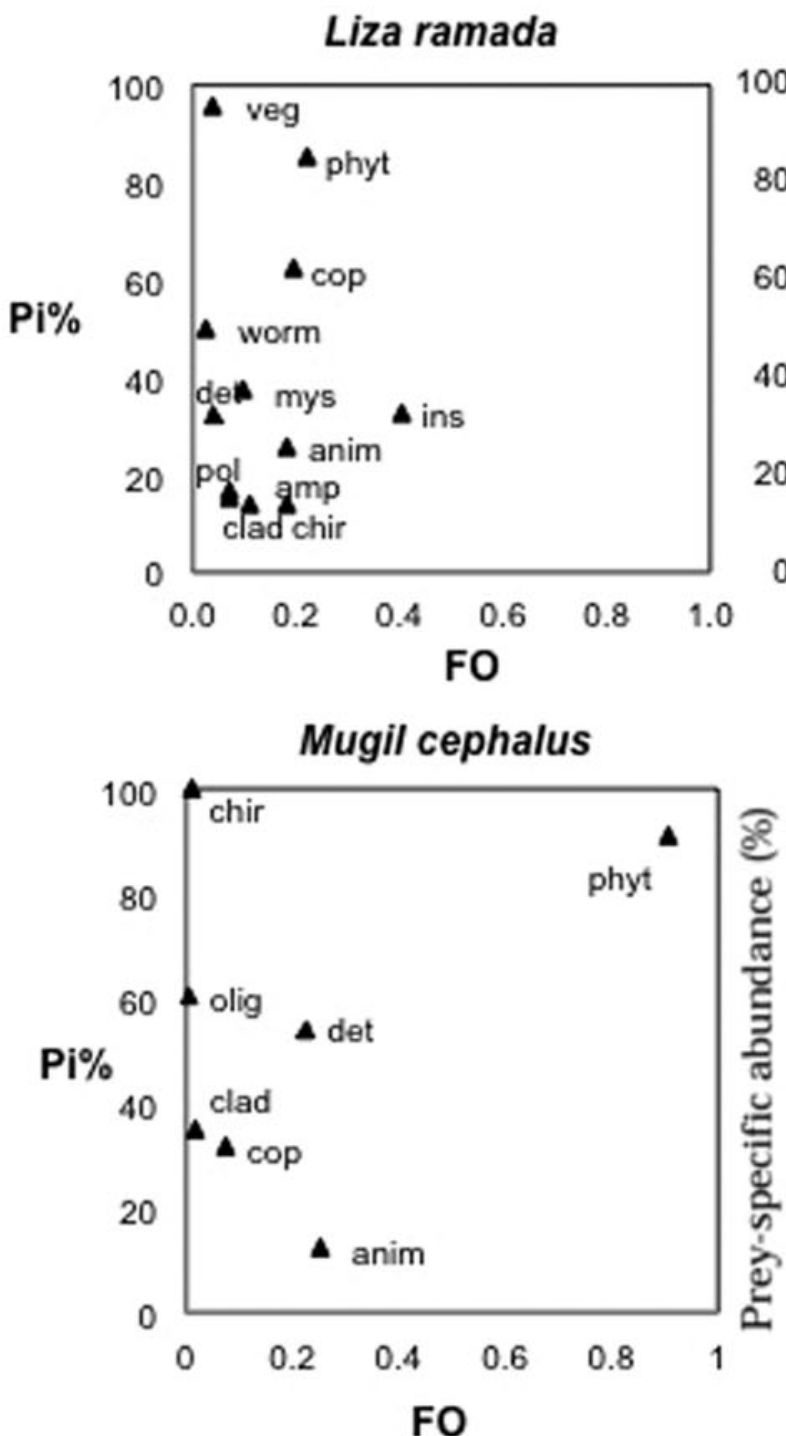

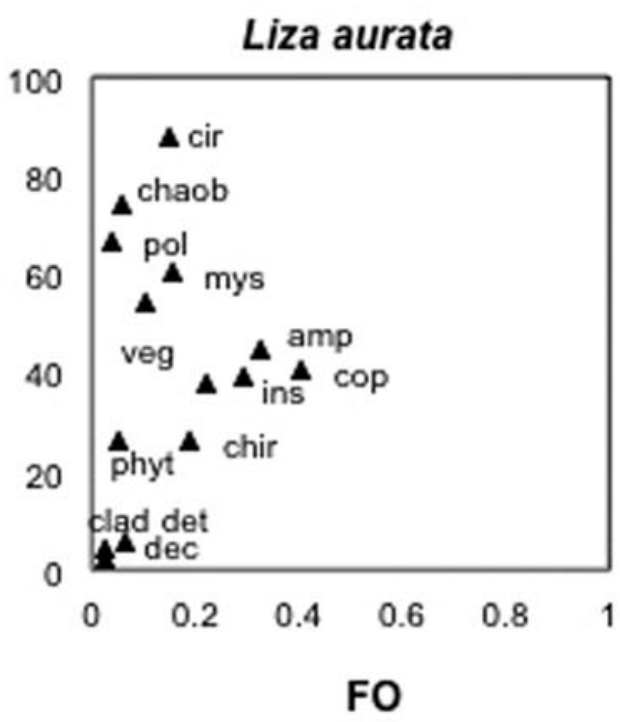

Liza saliens
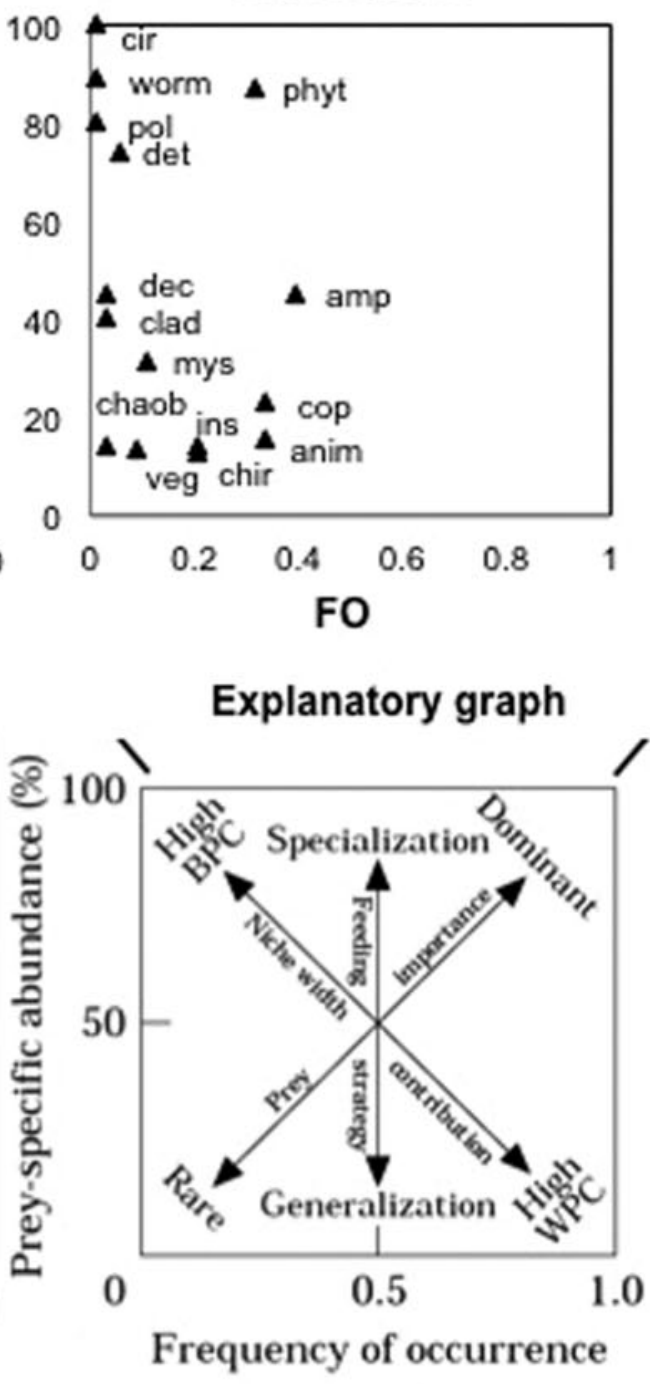

Fig. 3. Relationship between the prey-specific abundance (Pi) and the frequency of occurrence (\% FO) of the food categories of the Mugilidae species collected in the estuarine systems of Strymonikos Gulf during the sampling period of the current study. The plots are based on the modified Costello graphical method (Amundsen et al., 1996). An explanatory graph for the interpretation of the method is given. BPC, between-phenotype component to niche width; WPC, within-phenotype component (references in Amundsen et al., 1996). det, detritus; phyt, microalgae; veg, aquatic vegetation; olig, Oligochaeta; chir, Chironomidae; clad, Cladocera; cop, Copepoda; anim, unidentified invertebrates; ins, unidentified insects; pol, Polychaeta; chaob, Chaoborus sp.; amp, Amphipoda; mys, Mysidacea; cirr, Cirripedia; dec, Decapoda. 
change their feeding habits according to their life cycle, and a variety of food items have been found in their stomachs (for a review, see De Silva, 1980; Brusle, 1981; Cardona, 2016). Differences with other studies could be attributed to different prey availability, different inter-species competition or different sizes or ages of fishes concerned. For instance, in the south-eastern Aegean Sea, L. ramada individuals (age 1-6 years) had the highest percentage (98\%) of microalgae in their diet regardless of the season (Kasimoğlu \& Yilmaz, 2012). In this study, the consumption of microalgae by $L$. ramada was much lower (only in spring in Strymon did it reach $43 \%$ ), but also the specimens were younger (presumably less than 3 years when they first reach their first maturity (Koutrakis, 2011)).

Our data support Mugilidae's opportunistic character that has also been found by others (Bartulović et al., 2007; Lebreton et al., 2011). The seasonal and spatial differences in diet composition of the same species support these findings, and also suggest that species change their diet according to food availability. Discrepancies in the diet composition between the two areas reflect differences in prey availability (Cabral, 2000). Mugil cephalus, which is frequently caught in Richios in summer and autumn, had a higher feeding intensity and consumed a relatively higher percentage of microalgae. Microalgae seemed to be consumed more in Richios compared with Strymon, also by C. labrosus and L. saliens, possibly because this food source was more available in Richios. The high consumption of detritus in winter is possibly indicative of the limited food availability (Herder \& Freyhof, 2006). This pattern is common, especially for omnivorous species, which consume detritus when their preferred food items are not available (Bowen, 1983). Interspecific and intraspecific differences between different sampling periods and regions were also found by Almeida et al. (1993) and VerdiellCubedo et al. (2007a, b). Lebreton et al. (2013) also found differences between summer and spring in the stable isotope values of Liza aurata and L. ramada juveniles.

Consumption of microalgae or detritus could also be accidental while preying on benthic macroinvertebrates. This could be the case, for instance, for Chelon labrosus which consumes both microalgae and amphipods in high percentage (especially in autumn in Strymon and in summer and autumn in Richios), but rather not for M. cephalus, which, especially in summer and autumn in Richios, feeds almost exclusively on microalgae. The absence of linear relationships between microalgae/detritus and the benthic prey items implies intentional consumption of microalgae/detritus.

Diet also differed between sizes, as was found from the volumetric composition analysis. The contribution of microalgae was increased in the diet of the large class of three species, i.e. C. labrosus, L. ramada and $L$. saliens, but in some cases (e.g. in L. ramada in Richios) this was also due to the seasonal change. A similar shift in diet from microcrustaceans to microalgae was noted for $L$. aurata, $L$. ramada and $L$. saliens by Albertini-Berhaut $(1973,1975)$. Koussoroplis et al. (2010) also found a shift from planktonic to benthic food with the increase of the size of $L$. saliens juveniles. Ontogenetic diet shift to higher trophic level was also recorded with stable isotope analysis for juveniles of L. aurata and $L$. ramada (Lebreton et al., 2013). The diet of $L$. ramada in this study contains more animal prey compared with almost exclusively microalgae and debris that was found for adult specimens in a Portuguese estuary (Almeida, 2003). For $M$. cephalus consumption of animal prey decreases while consumption of phytoplankton increases and after reaching a total length of $50 \mathrm{~mm}$ they become exclusively vegetarian (De Silva, 1980 and references therein). As the permanova showed, both season and size are explaining the variation in diet, therefore it cannot always be clear if the differences in diet are ontogenetic or due to the seasonal differences in prey availability. Future studies taking into consideration the prey availability could better interpret the species diet preferences.

Chelon labrosus, L. saliens and M. cephalus showed the highest feeding intensity during summer and autumn when they were the most abundant in the total catches (Koutrakis, 2004). The higher presence and higher feeding intensity of the aforementioned species during summer and autumn may lead to the deduction that more food was available during that period. The higher feeding intensity could also be attributed to their need to compensate for the energy lost from migration. The Mugilidae species in the area have successive reproduction periods, and thus, when their feeding migration is towards the estuarine systems, different peaks of abundance are observed (Koutrakis, 2004). The co-occurrence of no more than two or three species at a time increases the utilization of available food and reduces competition.

In addition to food availability, environmental parameters influence feeding habits. Temperature and salinity are among the most important factors, and they usually have a negative effect on feeding intensity (Williams \& Williams, 1991; Jardas et al., 2004; Hammerschlag et al., 2010). Our results do not show a clear pattern of salinity having a negative effect. However, in all cases where there was significant difference between the low and high salinity stations, the higher fullness index was reported in the less saline location. The results of the current study show that the three species have a higher feeding intensity in summer and autumn, when the water temperature is relatively higher. This pattern is also registered for other species (Vassilopoulou, 2006) and feeding intensity declines dramatically in winter for Mugilidae species, as summarized by Cardona (2016). Feeding intensity has also been correlated with fish size (Daly et al., 2009), but in the current study, the range of the total length values did not differ significantly between seasons. Therefore, length plays a relatively small role in feeding intensity.

The optimal foraging theory predicts that diet breadth increases when food is scarce (Schoener, 1971), and dietary breadth is known to increase when stomach fullness decreases (e.g. Vassilopoulou, 2006). However, similar patterns for the fullness index and the number of food items were found, as shown in the correspondence analysis. Food is probably not a limitation factor in the Strymonikos estuarine systems, as diet breadth did not increase when the fullness index decreased; thus, the latter is probably most influenced by factors other than food.

\section{Diet overlap}

Diet overlap among co-existing species is a valuable measure that facilitates the interpretation and understanding of the structure of fish assemblages. The high diet overlap between L. saliens and M. cephalus, as measured using Schoener's index, is due to the consumption of a high amount of microalgae, especially in the Richios estuarine system. The 
Table 6. Results on statistical significance $(P<0.05)$ of season and size class on explaining the variation in the trophic level per species and per systems, tested with general linear models. n.s., non-significant.

\begin{tabular}{|c|c|c|c|}
\hline Species & Parameter & Strymon & Richios \\
\hline \multirow[t]{2}{*}{ C. labrosus } & Season & n.s. & n.s. \\
\hline & Size & n.s. & $\begin{array}{r}P=0.013 \\
\quad(\text { class I })\end{array}$ \\
\hline \multirow[t]{2}{*}{ L. aurata } & Season & $P<0.011$ (autumn \& spring) & n.s. \\
\hline & Size & n.s. & n.s. \\
\hline \multirow[t]{2}{*}{ L. ramada } & Season & n.s. & n.s. \\
\hline & Size & $P<0.009$ (class I \& II) & $\begin{array}{c}P=0.001 \\
\quad(\text { class II })\end{array}$ \\
\hline \multirow[t]{2}{*}{ L. saliens } & Season & $P=0.041$ (summer) & n.s. \\
\hline & Size & $P=0.032($ class II $)$ & $\begin{array}{r}P<0.001 \\
\quad(\text { class I) }\end{array}$ \\
\hline \multirow[t]{2}{*}{ M. cephalus } & Season & n.s. & n.s. \\
\hline & Size & - & n.s. \\
\hline
\end{tabular}

aforementioned species had the highest feeding intensity and the highest overlap for the same seasons, probably because of the lack of strong trophic competition in this pair of species. Most of the species exhibited a moderate or low diet overlap in some seasons, because they do not share common trophic niches or they do not have a spatiotemporal overlap. Additionally, a difference in species or size of species constituting the same broad food category, such as unidentified insects, could occur. Identification was difficult, however, because many of these animals were well digested. High similarity in the diet of juvenile sympatric Mugilidae species has been recorded in other cases but differences were also revealed by isotopes or when considering particle size preferences (reviewed by Cardona, 2016). In general, we found lower diet overlap compared with that found between the same species in Ebro Delta, in Spain (Gisbert et al., 1995). However, it should be noted that the diet overlap was calculated with a different index, fishes were of smaller size and all seasons were lumped in the study in Spain.

As the diet overlap is not high between Mugilidae species in the estuarine systems in Strymonikos Gulf, food probably cannot be considered a strong factor that regulates the assemblage of Mugilidae species. However, in addition to food, environmental factors such as salinity are considered to have important effects on habitat selection (Cardona, 2006). According to Cardona et al. (2008), the structure of grey mullet assemblages inhabiting Mediterranean estuaries is determined by the salinity and by competitive interactions at the fry stage. Resource partitioning is also affected by trophic separation and spatial and temporal segregation (Ross, 1986).

\section{Feeding strategy}

The study of the feeding strategy (Costello method, modified by Amundsen) provides additional information on the feeding strategy and behaviours of species, and such information cannot usually be obtained solely through the volumetric method of diet analysis. Even though different food items were consumed by the studied species, the feeding strategy in four of them showed a rather similar pattern. Mugil cephalus was the most specialized feeder, with a preference for microalgae. Fry of M. cephalus also showed specialization in an estuarine area in Egypt, although there it consumed mostly zooplanktonic species (El-Ghobashy, 2009) as it was estimated using the frequency of occurrence method, which may overestimate prey items which are small in size. However, also in this study in Strymon river individuals of the first size class (comparable to those in Egypt) had a considerable amount of zooplankton groups (copepods and cladocerans). The feeding strategy of the rest of the species showed varying degrees of specialization at an individual level and of generalization in resource use. This generalization can be a potential mechanism for the coexistence of competitive species (Gabler \& Amundsen, 2010). As was expected, L. aurata seems to be a competitive species with generalized feeding strategy in population level and low diet overlap with the other species.

The fact that the multitude of food items within the diet seasonally changed for most of the studied species shows the flexibility of their feeding behaviour. The diet of juvenile striped bass (Morone saxatilis) in an estuary showed flexibility associated with prevailing salinity patterns, which may be an important mechanism in lowering juvenile mortality rates below the levels of earlier stages (Bounton \& Zion, 1981).

The graphs of the feeding strategy reflect the general pattern of species' strategy, however they cannot always be representative of the species' diet in each estuarine system and each season or size class as, due to the species' high mobility, uneven numbers of specimens were analysed per system or season.

\section{Trophic levels}

The variations in trophic levels that were calculated for the species in each season and estuarine system in some cases reflect the variations in their feeding habits, as they were described with the volumetric diet composition. For example, L. aurata had little variation in its trophic level, although the diet composition differed between seasons and systems. Apparently, the species can be feeding in the same trophic level but with different food items, probably choosing them according to their availability. Mugilidae are usually considered as low trophic level species, but here, values greater than 3 were recorded. This result agrees with Lebreton et al. (2011), who also recorded a high trophic level (at least secondary) for Mugilidae. Little seasonal variation in trophic levels was found, in contrast to Vinagre et al. (2012) who found that the trophic level, calculated with stable isotopes, of $L$. ramada may change by one trophic level between seasons.

In our study, there was no clear relationship found between the trophic level and the length for most of the species. There was a slight tendency of positive relation in L. ramada which agrees with Lebreton et al. (2013) who found higher stable nitrogen $\left(\delta^{15} \mathrm{~N}\right)$ values (indicative of the trophic level) for larger fishes. In general, from our data, a general pattern cannot be extracted for the variations of trophic level according to season, size or location. This also shows the opportunistic character of the species that seem to use the available resources each time.

\section{CONCLUSION}

In conclusion, the Mugilidae in the Strymonikos estuarine systems do not seem to compete for common resources, 
probably because the species do not have a spatiotemporal overlap, enough food is available, or they utilize different resources. However, it cannot be excluded that their distribution is affected by food availability, as suitable food is among other factors (e.g. salinity, substratum, turbidity) that influence species distribution (summarized by Koutrakis, 2016). The results of the present study represent the first data on diet composition, feeding strategy and diet overlap between coexisting juveniles of the Mugilidae species in the estuaries of Strymonikos Gulf. These data are applicable as a reference for future comparative studies and for fishery management and conservation in the area. The data from the present study can also be useful in trophic models of aquatic ecosystems (e.g. Christensen \& Pauly, 1992; Walters et al., 1997). A drawback of our study is that the sample size was not sufficient to make all analyses possible per species, season, location and size at the same time. However, our results contribute to the better understanding of the complex interactions between coexisting juvenile fishes and their use of estuarine systems for nurseries. Follow-up studies on the feeding habits of juvenile Mugilidae species in the area (e.g. investigation of possible changes) could be supported by modern techniques of feeding ecology, such as stable isotope analysis (Araújo et al., 2007; Lebreton et al., 2011, 2013) or fatty acid analysis (Koussoroplis et al., 2010), that can provide integrated information on longer-term diets.

\section{ACKNDWLEDGEMENTS}

The collection of specimens was conducted during the EU cofunded LIFE project entitled 'Concerted actions for the management of the Strymonikos coastal zone' and was carried out by the Fisheries Research Institute of Kavala, Greece. The authors would like to thank Louis Gower for the language correction of the manuscript, Dietmar Straile and the stable isotope group of the Limnological Institute, University of Konstanz, for fruitful discussions and Elizabeth Yohannes and five anonymous referees for commenting on earlier versions of the manuscript. Ioanna Salvarina was a member of International Max Planck Research School (IMPRS) for Organismal Biology, Germany and she thanks Karl-Otto Rothhaupt for general support and the Academic Staff Development of the University of Konstanz, Germany, for the language polishing grant for an earlier version of the manuscript.

\section{REFERENCES}

Albertini-Berhaut J. (1973) Biologie des stades juvéniles de Télostéens Mugilidae Mugil auratus Risso, 1810, Mugil capito Cuvier, 1829 et Mugil saliens Risso, 1810. I - Régime alimentaire. Aquaculture 2, $251-266$.

Albertini-Berhaut J. (1975) Allométrie chimique et changement de régime alimentaire chez Mugil capito (Téléostéen, Mugilidae). Comptes rendus de l'Académie des Sciences, Paris 280, 297-300.

Albertini-Berhaut J. (1978) Croissance lineaire et ponderale de $M$ auratus dans le Golfe de Marseille a celle de M. capito. Cybium, ze serie 4, 51-6o.

Almeida P.R. (2003) Feeding ecology of Liza ramada (Risso, 1810) (Pisces, Mugilidae) in a south-western estuary of Portugal. Estuarine, Coastal and Shelf Science 57, 313-323.
Almeida P.R., Moreira F., Costa J.L., Assis C.A. and Costa M.J. (1993) The feeding strategies of Liza ramada (Risso, 1826) in fresh and brackish water in the River Tagus, Portugal. Journal of Fish Biology 42, 95-107.

Amundsen P.A., Gabler H.M. and Staldvik F.J. (1996) A new approach to graphical analysis of feeding strategy from stomach contents datamodification of the Costello (1990) method. Journal of Fish Biology $48,607-614$.

Araújo M.S., Bolnick D.I., Machado G., Giaretta A.A. and dos Reis S.F. (2007) Using $\delta^{13} \mathrm{C}$ stable isotopes to quantify individual-level diet variation. Oecologia 152, 643-654.

Bartulović V., Glamuzina B., Lučić D., Conides A., Jasprica N. and Dulčić J. (2007) Recruitment and food composition of juvenile thinlipped grey mullet, Liza ramada (Risso, 1826), in the Neretva River estuary (Eastern Adriatic, Croatia). Acta Adriatica 48, 25-37.

Bartulović V., Matić-Skoko S., Lučić D., Conides A., Jasprica N., Joksimović A., Dulčić J. and Glamuzina B. (2009) Recruitment and feeding of juvenile leaping grey mullet, Liza saliens (Risso, 1810) in the Neretva River estuary (south-eastern Adriatic, Croatia). Acta Adriatica 50, 91-104.

Bounton W.R. and Zion H.H. (1981) Importance of juvenile striped bass food habits in the Potomac Estuary. Transactions of the American Fisheries Society 110, 56-63.

Bowen S.H. (1983) Detritivory in neotropical fish communities. Environmental Biology of Fishes 9, 137-144.

Brusle J. (1981) Food and feeding in grey mullet. In Oren O.H. (ed.) Aquaculture of grey mullets. Cambridge: Cambridge University, Press p. 507.

Budge S.M., Iverson S.J. and Koopman H.N. (2006) Studying trophic ecology in marine ecosystems using fatty acids: a primer on analysis and interpretation. Marine Mammal Science 22, 759-801.

Cabral H.N. (2000) Comparative feeding ecology of sympatric Solea solea and $S$. senegalensis, within the nursery areas of the Tagus estuary, Portugal. Journal of Fish Biology 57, 1550-1562.

Cambrony M. (1984) Identification et périodicité du recrutement des juveniles de Mugilidae dans les étangs littoraux du LanguedocRoussillon. Vie et Milieu 34, 221-227.

Campo D., Mostarda E., Castriota L., Scarabello M.P. and Andaloro F. (2006) Feeding habits of the Atlantic bonito, Sarda sarda (Bloch, 1793) in the southern Tyrrhenian sea. Fisheries Research 81, 169-175.

Cardona L. (1999) Seasonal changes in the food quality, diel feeding rhythm and growth rate of juvenile leaping grey mullet Liza saliens. Aquatic Living Resources 12, 263-270.

Cardona L. (2001) Non-competitive coexistence between Mediterranean grey mullet: evidence from seasonal changes in food availability, niche breadth and trophic overlap. Journal of Fish Biology 59, 729-744.

Cardona L. (2006) Habitat selection by grey mullets (Osteichthyes: Mugilidae) in Mediterranean estuaries: the role of salinity. Scientia Marina $70,443-455$.

Cardona L. (2016) Food and feeding of Mugilidae. In Crosetti D. and Blaber S. (eds) Biology, ecology and culture of grey mullet (Mugilidae). Boca Raton, FL: CRC Press, pp. 165-195.

Cardona L., Hereu B. and Torras X. (2008) Juvenile bottlenecks and salinity shape grey mullet assemblages in Mediterranean estuaries. Estuarine, Coastal and Shelf Science 77, 623-632.

Castriota L., Scarabello M.P., Finoia M.G., Sinopoli M. and Andaloro F. (2005) Food and feeding habits of pearly razorfish, Xyrichtys novacula (Linnaeus, 1758), in the southern Tyrrhenian Sea: variation by sex and size. Environmental Biology of Fishes 72, 123-133. 
Christensen V. and Pauly D. (1992) ECOPATH-II: a software for balancing steady-state ecosystem models and calculating network characteristics. Ecological Modelling 61, 169-185.

Clarke K.R. and Gorley R.N. (2001) PRIMER v5: user manual/tutorial. Plymouth: PRIMER-E, $91 \mathrm{pp}$.

Daly E.A., Brodeur R.D. and Weitkamp L.A. (2009) Ontogenetic shifts in diets of juvenile and subadult Coho and Chinook Salmon in coastal marine waters: important for marine survival? Transactions of the American Fisheries Society 138, 1420-1438.

De Silva S.S. (1980) Biology of juvenile grey mullet: a short review. Aquaculture 19, 21-36.

Digby P.G.N. and Kempton R.A. (1987) Multivariate analysis of ecological communities. London: Chapman and Hall, $206 \mathrm{pp}$.

Eggold B.T. and Motta P.J. (1992) Ontogenetic dietary shifts and morphological correlates in striped mullet, Mugil cephalus. Environmental Biology of Fishes 34, 139-158.

El-Ghobashy A.E. (2009) Natural fish fry food of seven commercial species in the Egyptian Mediterranean Water. World Applied Sciences Journal 7, 320-331.

Froese R. and Pauly D. (eds) (2010) FishBase. World Wide Web electronic publication. Available at http://www.fishbase.org, version (05/2010)

Gabler H.-M. and Amundsen P.-A. (2010) Feeding strategies, resource utilisation and potential mechanisms for competitive coexistence of Atlantic salmon and alpine bullhead in a sub-Arctic river. Aquatic Ecology 44, 325-336.

Gisbert E., Cardona L. and Castelló F. (1996) Resource partitioning among planktivorous fish larvae and fry in a Mediterranean coastal lagoon. Estuarine, Coastal and Shelf Science 43, 723-735.

Gisbert E., Cardona L. and Castelló Orvay F. (1995) Alimentación de los alevines de mugílidos en el delta del Ebro. Miscellania Zoologica 18 $145-151$.

Hammerschlag N., Ovando D. and Serafy J.E. (2010) Seasonal diet and feeding habits of juvenile fishes foraging along a subtropical marine ecotone. Aquatic Biology 9, 279-290.

Herder F. and Freyhof J. (2006) Resource partitioning in a tropical stream fish assemblage. Journal of Fish Biology 69, 571-589.

Hureau J.C. (1966) Biologie comparée de quelques poissons antartique (Nototheniidae). Bulletin of the Institute of Oceanography of Monaco $68,1-244$.

Hyslop E.J. (1980) Stomach content analysis - a review of methods and their application. Journal of Fish Biology 17, 411-429.

Ingram B. and De Silva S. (2007) Diet composition and preference of juvenile Murray cod, Trout cod and Macquarie perch (Percichthyidae) reared in fertilised earthen ponds. Aquaculture 271, 260-270.

Jardas I., Santic M. and Pallaoro A. (2004) Diet composition and feeding intensity of horse mackerel, Trachurus trachurus (Osteichthyes: Carangidae) in the eastern Adriatic. Marine Biology 144, 1051-1056.

Kasimoğlu C. and Yilmaz F. (2012) Feeding habits of the thin-lipped grey mullet, Liza ramada, in Gökova Bay in the southern Aegean Sea. Zoology in the Middle East 56, 55-61.

Katselis G., Hotos G., Minos G. and Vidalis K. (2006) Phenotypic affinities on fry of four Mediterranean grey mullet species. Turkish Journal of Fisheries and Aquatic Sciences 6, 49-55.

Katselis G., Koukou K., Dimitriou E. and Koutsikopoulos C. (2007) Short-term seaward fish migration in the Messolonghi-Etoliko lagoons (Western Greek coast) in relation to climatic variables and the lunar cycle. Estuarine, Coastal and Shelf Science 73, 571-582.

Koussoroplis A.-M., Bec A., Perga M.-E., Koutrakis E., Desvilettes C. and Bourdier G. (2010) Nutritional importance of minor dietary sources for leaping grey mullet Liza saliens (Mugilidae) during settlement: insights from fatty acid $\delta^{13} \mathrm{C}$ analysis. Marine Ecology Progress Series 404, 207-217.

Koutrakis E.T. (2004) Temporal occurrence and size distribution of grey mullet juveniles (Pisces, Mugilidae). Journal of Applied Ichthyology 20, $76-78$.

Koutrakis E.T. (2011) Reproductive biology of two grey mullet species (Actinopterygii: Mugiliformes: Mugilidae) in a northern Aegean Sea estuarine system. Acta Ichthyologica et Piscatoria 41, 37-46.

Koutrakis E. (2016) Biology and ecology of fry and juveniles of Mugilidae. In Crosetti D. and Blaber S. (eds) Biology, ecology and culture of grey mullet (Mugilidae). Boca Raton, FL: CRC Press, pp. 264-292.

Koutrakis E.T., Kallianiotis A. and Tsikliras A. (2004) Temporal patterns of larval fish distribution and abundance in a coastal area of Northern Greece. Scientia Marina 68, 585-595.

Koutrakis E.T., Kokkinakis A.K., Eleftheriadis A.E. and Argiropoulou M.D. (2000) Seasonal changes in distribution and abundance of the fish fauna in the two estuarine systems of Strymonikos gulf (Macedonia, Greece). Belgian Journal of Zoology 130, 41-48.

Koutrakis E.T., Sinis A.I. and Economidis P.S. (1994) Seasonal occurrence, abundance and size distribution of grey mullet fry (Pisces, Mugilidae) in the Porto-Lagos lagoon and Lake Vistonis (Aegean Sea, Greece). Israeli Journal of Aquaculture - Bamidgeh 46, 182-196.

Lebedev N.V. (1946) Elementary populations of fish. Zoologicheskii Zhurnal 25, 121-135. [In Russian]

Lebreton B., Richard P., Guillou G. and Blanchard G.F. (2013) Trophic shift in young-of-the-year Mugilidae during salt-marsh colonization. Journal of Fish Biology 82, 1297-1307.

Lebreton B., Richard P., Parlier E.P., Guillou G. and Blanchard G.F. (2011) Trophic ecology of mullets during their spring migration in a European saltmarsh: a stable isotope study. Estuarine, Coastal and Shelf Science 91, 502-510.

Pauly D., Froese R., Sa-a P., Palomares M.L., Christensen V. and Rius J. (2000) TrophLab manual. Manila: ICLARM.

Pauly D., Trites A., Capuli E. and Christensen V. (1998) Diet composition and trophic levels of marine mammals. ICES Journal of Marine Science 55, 467-481.

R Development Core Team (2012) $R$ : a language and environment for statistical computing. Vienna: $\mathrm{R}$ Foundation for Statistical Computing. Available at http://www.R-project.org/.

Romo S., Fernández F., Ouahid Y. and Barón-Sola A. (2012) Assessment of microcystins in lake water and fish (Mugilidae, Liza sp.) in the largest Spanish coastal lake. Environmental Monitoring and Assessment 184, 939-949.

Ross S.T. (1986) Resource partitioning in fish assemblages: a review of field studies. Copeia 2, 352-388.

RStudio Team (2015) RStudio: integrated development for R. Boston, MA: RStudio, Inc. Available at http://www.rstudio.com/.

Schoener T.W. (1970) Nonsynchronous spatial overlap of lizards in patchy habitats. Ecology 51, 408-418.

Schoener T.W. (1971) Theory of feeding strategies. Annual Review of Ecology and Systematics 2, 369-404.

Stamatis N., Ioannidou D. and Koutrakis E. (2001) Monitoring of key eutrophication parameters at three inshore stations of Strymonikos Gulf, north Aegean Sea. Fresenius Environmental Bulletin 10, $706-710$.

Stergiou K.I. and Karpouzi V.S. (2002) Feeding habits and trophic levels of Mediterranean fish. Reviews in Fish Biology and Fisheries 11, 217-254. 
Vassilopoulou V. (2006) Dietary habits of the deep-sea flatfish Lepidorhombus boscii in north-eastern Mediterranean waters. Journal of Fish Biology 69, 1201-1220.

Verdiell-Cubedo D., Egea-Serrano A., Oliva-Paterna F.J. and Torralva M. (2007a) Biología trófica de los juveniles del género Liza (Pisces: Mugilidae) en la laguna costera del Mar Menor (SE Península Ibérica). Limnetica 26, 67-73.

Verdiell-Cubedo D., Oliva-Paterna F.J. and Torralva M. (2007b) The effects of competitors on fitness of marbled goby Pomatoschistus marmoratus (Pisces, Gobiidae) in the Mar Menor coastal lagoon (SE Iberian Peninsula). Italian Journal of Zoology 74, 69-177.

Vinagre C., Salgado J.P., Mendonça V., Cabral H. and Costa M.J. (2012) Isotopes reveal fluctuation in trophic levels of estuarine organisms, in space and time. Journal of Sea Research 72, 49-59.

Wallace R.K. (1981) An assessment of diet-overlap indexes. Transactions of the American Fisheries Society 110, 72-76.
Walters C., Christensen V. and Pauly D. (1997) Structuring dynamic models of exploited ecosystems from trophic mass-balance assessments. Reviews in Fish Biology and Fisheries 7, 139-172.

and

Williams M.D. and Williams W.D. (1991) Salinity tolerances of four species of fish from the Murray-Darling river system. Hydrobiologia $210,145-160$

\section{Correspondence should be addressed to:}

I. Salvarina

Limnological Institute, University of Konstanz, Mainaustr. 252, 78464, Konstanz, Germany email: isalvarina@gmail.com 